\title{
"It stays with me": The experiences of second- and third-year Student Nurses when caring for patients with cancer
}

\section{European Journal of Cancer Care (2013)}

Article first published online: 18 OCT 2013 | DOI: 10.1111/ecc.12139

\begin{abstract}
Little is known about student nurses experiences of nursing patients with cancer in the UK. With the increasing survival of people with cancer and with cancer no longer seen as a terminal illness it is useful to understand student nurses clinical experience when nursing those with cancer. This study takes a phenomenological approach involving three focus group interviews with twenty student nurses from the second and third year of their course in one centre in the UK. All the students had experience of caring for patients with cancer. The key themes emerging from the study were: Communication, Impact on Self, Lack of Support and End-of-Life-Care. Students emphasized the need to have more knowledge and support in relation to cancer care. They describe how they lack communication skills and found it difficult to handle their emotions. A number of students found the whole experience of caring for patients with cancer emotionally distressing and draining and they describe avoiding contact with these patients by using distancing and avoidance strategies. Student nurses need additional support through demystifying cancer, using reflective practice and good mentoring in the clinical area to enable students to feel supported, and develop confidence in their capacity for care for people with cancer.
\end{abstract}

Key words: cancer, emotions, communication, education, student nurses 


\section{Literature Review}

Many studies identify the importance of nurses developing therapeutic relationships with patients especially those suffering from serious illness such as cancer so that comfort is provided and symptoms managed (Smith \& Gray 2001; Iranmanesh et al. 2009). However there is evidence of negative attitudes towards cancer that seem to be shared not only by the public (Sontag 1979) but also by nurses and other health care professionals and clinical experience with patients with cancer may reinforce negative attitudes (Corner 1993; Kearney et al. 2003). Student nurses were found to equate cancer with death and described feeling fearful and felt: 'there wasn't a lot you can do' about cancer (Sanford et al. 2011; Cunningham et al. 2006). However around 1.8 million people in England are living beyond a diagnosis of cancer therefore pessimism may be misplaced (DH 2012). Furthermore nursing students are socialized into a care/cure dichotomy where high technological care for younger people is more appealing than care for older people with chronic illnesses and this 'acute' orientation develops over the three years of the pre-registration course with many people with cancer in the older age group (Smith 1992). The issue of the global rise of non-communicable diseases (NCD) such as cancer, cardiovascular disease and pulmonary disease is increasingly discussed as a significant issue and one where nurses need to be prepared to improve health outcomes in all contexts with patients with NCDs (Hughes et al. 2012).

In a mixed methods study involving a self report questionnaire $(n=167)$ and focus groups $(n=24)$ with student nurses in Turkey regarding their experiences of caring for patients with cancer it was found that $94 \%$ of the students reported a need for more information about cancer (Kav et al. 2012). A number of studies identify how student nurses feel depressed when caring for people with cancer and worry about the potential for harm such as causing patients to have an infection or causing pain (Kav et al. 2012; Sanford et al. 2011; Mohan et al. 2005). Student nurses also identified a lack of support and guidance related to care of patients with cancer in the clinical setting, despite the lectures provided at universities (Hjörleifsdóttir \& Carter 2000). 
A recurring theme in many studies is the problems experienced both by trained nurses and student nurses regarding communication with those with cancer (Corner 1993; Wilkinson 1991; Wood \& Ward 2000). Student nurses report feeling fearful of saying the wrong thing to patients, describing their communication skills as superficial and worry about breaking down and crying in front of patients (Kav et al. 2012). Students are being trained with high technology simulation exercises, which aim to improve their technical nursing skills (Hyland \& Hawkins 2009), but in contrast describe feeling helpless and inadequate when it comes to emotional and psychosocial aspects of care including the management of pain (Knight \& Field 1981; Fabricius 1991, Mohan et al. 2005; Sadala \& da Silva, 2009). Student nurses identify their curative orientation towards care and treatment by speaking about not being able to stop the progress of cancer (Mohan et al. 2005). For some students the word cancer was linked with death and student nurses' have been found to feel overwhelmed by fear of death (Schrock \& Swanson 1981).

According to Smith (1992) being a caring person is part of a 'package' of being a nurse. Smith discusses the concept of emotional labour (EL), as the nurses' involvement with patients, which promotes an intimate and therapeutic relationship. Relationship building is the core skill of communication, which builds trust and mutual admiration (Sparks \& Villagran 2010). For many authors the management of emotions forms a core aspect of EL (James 1989; Smith \& Gray 2001; Hoschild 1983). Smith (1992) found that student nurses develop negative strategies to protect and distance themselves emotionally against strong feelings such as failure, anger, guilt and this can lead them to withhold emotional labour with patients. Patients with cancer on general wards describe how staff did not always understand how frightening the experience of cancer was and healthcare assistants describe cancer as mysterious (Wood \& Ward 2000). Nonspecialist trained staff identify communication issues with cancer patients as: 'I don't see many cancer patients it is scary knowing what to do or say' (Wood \& Ward 2000: 194). Student nurses may find themselves in a difficult position when they have to do emotional labour with people with cancer particularly when the student's experience may be in non-specialist settings. The aim of this article is to explore the experience of student nurses when caring for people with cancer during their clinical placements. 


\section{Aim of research}

To explore second and third year student nurses' experiences of caring for patients with cancer during clinical placements.

\section{Method}

A qualitative, descriptive level of inquiry was utilized in this study to describe student nurses experiences of caring for cancer patients, during their clinical placements. The study used a phenomenological approach to explore and describe (Wojnar \& Swanson 2007) the phenomena of the experience and meanings that student nurses attach to caring for patients with cancer and for the researcher to begin to understand student nurses experiences and meanings (Morse \& Field 1995). A study was designed to enable the researcher to ask the question 'how' to find out about particular experiences and then to answer the 'why' question by examining the wider contexts in which the phenomena of caring for those with cancer arises (Silverman 2011: 17).

Due to the centrality of student's experience in the research question; a method exploring subjective experiences was chosen to discover the essence of subjective human experience (Meleis 1996), and to yield rich data from participants. Focus group interviews, which were audio-recorded, were conducted in the months of May-June 2012 in one school of nursing. Focus groups were thought the most appropriate method for collecting data, as they allow for obtaining rich data through an organized discussion (Krueger 1988; Denzin 1989) with a selected group of individuals, who share similar experiences, views, and perceptions, (Barbour \& Kitzinger 1990). An interview guide was used whereby an introductory broad question was asked: 'Can you tell me where you're from and where you've worked in practice placements?' This was followed by another question: 'How do you experience caring for cancer patients?' Specific questions about feelings were also asked: 'How did you feel caring for cancer patients?' followed by: 'Can you tell me more about that experience?' A closing question: 'Is there anything else you would like to share?' was asked at the end of each focus group interview. 


\section{Focus group interviews and phenomenology}

The use of phenomenology for focus group interviews has been debated in relation to its methodological fit. On one hand, there is a viewpoint that phenomena can only be described by the person who experiences it, which is confined to that person's experience (Webb \& Kevern 2001; Webb 2003). Authors who share this view emphasize that individual interviews maintain an "uncontaminated" perspective as it is conducted with one interviewer and one respondent. They argue that the "true essence" of the experience may not be preserved in focus group interviews, as other persons' views may influence or alter an understanding of the phenomena. This they believe may allow the researcher to misconstrue the true meaning of the lived experience (Webb \& Kevern 2001).

On the other hand, an opposing perspective is that the true meanings of individual lived experiences are preserved in focus group interviews (Bradbury-Jones, Sambrook \& Irvine 2009). Each participant's narrative facilitates reflection and deeper insight by other participants, which fosters both individual and shared meanings (Sorrell \& Redmond 1995). Authors who share this view highlight that this method of inquiry facilitates dialogue thereby allowing clarification of specific phenomena (Co^te'-Arsenault \& Morrison-Beedy 2001), which supports this study. It is incumbent for researchers utilizing focus group interviews to ensure that the philosophical underpinnings of their work are clearly examined (Bradbury-Jones, Sambrook \& Irvine 2009).

The nature of this study requires the use of phenomenology to explore and understand student nurses' experiences of caring for cancer patients (Husserl 2001). Focus group allows the researcher to engage with persons who share similar characteristics and experiences in relation to the phenomena of interest. The participants in this study are all student nurses in the same institution; and they share the same purpose, in that, they are being trained to care for patients (Krueger \& Casey 2000). This method does not only create a unique platform for both the researcher and participants, which shapes the process of the interview (Sorrell \& Redmond 1995), and facilitates exploration of phenomena. It also complements phenomenology, in that, persons who share common interests, goals and experiences are more amenable to share their experiences with 
others who have a similar experience and understanding of their journey which stimulates discussions and potentially a greater understanding of the phenomena under study (Bradbury-Jones, Sambrook \& Irvine 2009; Sorrell \& Redmond 1995). Participants can expound or defend their views based on other participants' contributions and expressions (Wilkinson 1998). The researcher's assumptions are challenged by participants' contributions, which promote validation, thus allowing phenomena to remain in its purest form and in this way complements phenomenology (Halling \& Leifer 1991; Halling, Kunz \& Rowe 1994).

\section{Participants}

Following submission to the university ethics committee a favorable opinion was achieved enabling the study to commence. Purposive sampling resulted in 20 volunteer undergraduate Baccalaureate and Diploma nursing students being recruited to the study, which enabled three focus group interviews to be held. The inclusion criteria limited participants to those that provided care for at least one cancer patient during their clinical placements, and were in their second or third year of the nursing course. The first focus group consisted of 1 male and 8 female second-year student nurses. The second group included 4 second-year female student nurses, and the third focus group consisted of seven female third year-student nurses. All focus groups were conducted in a quiet, private area within the university that was convenient for students. The focus groups lasted between 1 to 2 hours and light snacks and drinks were provided by the researcher.

In a qualitative research, credibility refers to the trustworthiness of the interpretations (Lacey 2006) and representativeness and transferability of the data and findings (Topping 2006; Denzin 1989). Attending a workshop on reflexivity facilitated the researcher to be reflexive by using a research diary and keeping diary entries of personal feelings immediately after focus group interviews (Langridge 2007). This process including feedback from the research supervisor enabled a rigorous style of facilitation to be developed, which shaped the direction of the focus group interviews, to focus on the students lived experience and enabling an inclusive approach to participants and preventing the dominance of any one individual during discussion. Participants' own words were used in the presentation of findings, which maintained credibility of the themes and method of data analysis. 


\section{Data Analysis}

The audio recordings were listened to many times while reading through the transcribed data to enable the researcher to become immersed in what participants said and familiar with participants words. Open coding was achieved by line by line analysis to identify and extract significant words and statements and identify themes, in accordance with Colaizzi's (1978) seven-step methodological approach. Thematic analysis and metacoding enabled relationships among themes to be examined, which facilitated the process of horizontalization. Formulated meanings were constructed and organized in cluster themes, which facilitated further identification of key themes. Themes were then examined for common links and divided into sub themes, which highlighted insights into student nurses' experiences of caring for cancer patients.

\section{Findings}

Five themes were uncovered from the data through using descriptive phenomenology: the key theme was: Communication with patients, followed by Impact on Self, 'I feel lost', 'we should be prepared', cancer and end- of-Life.

\section{Communication with Patients}

Students discussed how their communicated personal experiences and interactions with people with cancer during their clinical placements. Marie describes how she allows patients to express themselves:

Marie: "Being quiet... allows them to experience the emotion...It says I'm right here with you... I held his hand... establish a rapport with the family...... put your arm around them...say to them, 'how do you feel today?'... They might open up...contact can help. They've got a personality. They've got cancer now...they've had a life before... It helps me to better communicate with the patient and relatives other than 'are you in pain, 'its background knowledge"

Marie describes how she uses key communication skills to enable patients to express their emotions. She describes being quiet and listening, using open-ended questions such as "how do you feel?" and empathy through touch. She sees that the contact she 
has with patients and with the family helps patients "open up", which enables her to know how they feel. Marie recognizes the importance of patients' and family's feelings. Marie is skilled in identifying the holistic needs of the patient. She mentions "background knowledge", of the patient, which is the basis of building a therapeutic relationship with the patient, and a means of interacting with them as unique individuals. Marie identifies important aspects of emotional labour, such as building trust through touch and using the language of therapeutic nursing such as 'feel', 'open up'. 'helps me' 'background knowledge' (Smith 1992; Theodosius 2008).

Ruby shares her experiences as she describes how she takes the opportunity to chat with the patient after assessing their vital signs, as her strategy in communicating with cancer patients and families.

Ruby: "I do my observations, I'll ask them, 'Can I?' before I sit with them. First, I try to make sure that they're comfortable and relaxed. I held a patient's hand...didn't say anything...she said, when people see her, they run and keep their distance...She said it was comforting that I held her hand... that I actually looked at her. It's important to treat the patient as a human being"

Ruby's approach was significant, as she gained the patient's permission before sitting with her. This asking permission to talk with patients with cancer by student nurses has also been found in another study (Hjörleifsdóttir \& Carter 2000). The patient describes to Ruby how some people avoid her by keeping their distance not an uncommon experience of patients with cancer (Wood \& Ward 2000). Ruby describes her confidence at initiating a therapeutic relationship by giving time, using silence and the nonverbal communication skill of touch, all aspects of empathy (Wilkinson 1991). Ruby describes the positive feedback she receives regarding her care from the patient "she said that it was comforting that I held her hand". Ruby and Marie have a background as health care assistants and describe feeling prepared for nursing people with cancer as they have sensitive, facilitative communication skills and demonstrate their ability to do emotional labour developed over many years in their previous roles as health care assistants. In contrast to Ruby and Marie many of the students described difficult moments when nursing people with cancer in particular the impact of this contact on their selves, which is discussed next.

\section{Impact on Self}


Students described experiences of caring for cancer patients that changed them, creating a lasting impression on their selves and their minds. Lily expresses concerns about her inability to make jokes, as she describes herself as a jolly person, and finds it difficult when she interacts with cancer patients.

Lily: “...you have to be careful...I like to joke too much... Some people don't like joking"

Marie:" Jokes may not be appropriate”

Lily: "I don't like it... eventually...you no longer smile. If you have a caring heart...you feel sorry for people as they're suffering"

Lily, like Marie, believes 'being sympathetic' is the professional image she should project to cancer patients, as opposed to her jolly and joking personality. She finds this challenging, as it affects her real self, as she emphasizes, "eventually...you no longer smile". Both Lily and Marie share the perceptions of society, in adopting a 'walking on eggshells' approach to people with cancer (Sales 2010) by refraining from sharing jokes, although research studies have shown that cancer patients are aware of changes in how they are treated socially because they have cancer (Jarrett \& Payne 2000).

There is conflict between Lily's professional self and her real self, as she sobers up to being mature upon realizing the sadness people have to cope with when they have cancer. Lily easily adopts the compassionate and caring image that nurses project, described as 'niceness' (Li, 2004) and 'surface acting' (Hoschild 1983), as well as distancing, which allows the composure of self even under difficult circumstances. Lily represses her bubbly personality, which can result in an arrest of the real self, 'she no longer smiles' and adopts a professional persona 'feels sorry' to protect her real self and distance herself from the suffering patient (Jourard 1971).

Another student, Samantha, expresses how she does not like caring for cancer patients, although she understands the importance of having empathy and compassion when caring for patients with cancer, which she believes comes naturally with experience.

Samantha: "If I can switch anytime, I would...I don't like cancer care...you come across these people and it's your duty...but I don't like the effect it has on me...I feel like crying, I keep thinking about it" 
Samantha tries to adjust to her ethical duty of providing care, even if it means that she has to change her personal feelings, of not wanting to care for cancer patients, as it affects her emotionally. Samantha is very clear about her dislike of cancer care; she mentions "these people", which shows some level of detachment due to the negative effects of care on her emotions such as 'crying' and 'thinking about it'. This demonstrates her fears of the emotional effect of caring, which she sees as all negative.

Grace and Rita discuss similar experiences about how thoughts of caring for cancer patients have stayed in their minds.

Grace: "You take it home with you...its not something you can brush off...It stays in your mind all the time...you have no one to talk to............ So it stays with you"

Rita: "You're worrying about the littlest things in your life....'ve got my whole life ahead of me...yet l'm whining more than somebody who's dying...it stays in my mind"

Grace expresses her fears of changing to someone she does not want to be: a person heavily burdened with sadness, and describes this experience as "it stays with you" and "you have no one to talk to". Rita, like Grace, also reflects on the dying cancer patient and this puts things in perspective and reminds her to be thankful and appreciative of life rather than whining about insignificant things.

\section{'I feel lost'}

Communicating with cancer patients and dealing effectively with the emotional aspects of care were identified as skills that should be taught, practiced and developed:

Zoe: "There needs to be more emphasis on how to respond to patients.... feel lost when I go on placements, there's lots of cancer patients...instead of saying go read a book, sit and talk with us...!"

Zoe appears really frustrated and "lost" when in placements with people with cancer and feels that staff do not understand her needs. She wishes that the clinical staff would sit with her and help her to develop responding skills rather than being fobbed off and told to "go read a book". She would dearly like someone to sit and talk with her about how to respond to people with cancer and meet her own emotional needs. 
Victoria mentions specific skills she feels she should have as a third year student nurse:

Victoria: "We're in third year...they don't teach empathy nor compassion...they tell you that these are the qualities that they expect to see...we had a cancer lecture... basic. We never had a lecture that taught us how to break bad news...or communicate with the patients"

Victoria expresses her frustration about a lack of preparation and teaching on how to be empathetic and would like a focus on breaking bad news. In the third year of her course she expects to feel more skilled in the psychosocial aspects of care. Students are very aware of the need to be compassionate. Victoria wishes to be taught compassion and empathy as these skills, in her view, do not come naturally and should not be taken for granted. The lack of confidence identified by Victoria and Zoe related to breaking bad news and communication worries them now they are in the third year of their course and soon to be qualified nurses.

\section{'We should be prepared'}

Second and third year student nurses acknowledge that they had been given basic information regarding cancer, but collectively believe that more knowledge of cancer, and manifestations of the common types of cancer, should be embedded in their nursing programme.

Caitlin: "We're in second year and we've only had one lecture on cancer...very basic, we need lectures to deal with the emotional side of things"

Caitlin expresses the need for more lectures on the emotional areas of care, which she feels are neglected. She needs help to understand and respond appropriately to patients' feelings. This demonstrates how knowledgeable the students are about their need to manage the emotional aspects of care and how deficient and vulnerable they feel in this area.

Other students' views on support were more practice-oriented. Shannon and Ashley mention "symptoms" and preparation on what to do to recognize and provide care for cancer patients' symptoms. Ashley believes that observing cancer patients' treatment 
early on in the disease process will help him.

Shannon: "I think we should be prepared to deal with cancer patients depending on...symptoms and type of cancer"

Ashley: "I don't know much about the beginning of the disease process. Having a good placement where you can see the treatment of cancer patients with all various symptoms will be a good experience to learn"

Ashley views a "good" placement as one that would allow an active observation of different types of cancer treatment and management of symptoms particularly from the beginning of the disease. He mentions that he has a knowledge deficiency in the disease process at the initial phase, which displays his willingness and anticipation to learn. Other students felt "trapped" and "stagnant" in providing care for cancer patients, as seen below:

Megan: "Second year is more of having that level of information... to speak to a patient or family member...we're almost stagnant! We don't have enough understanding of cancer...it's common...it's a highly known subject...we're a bit trapped!"

Megan, like Ashley, Caitlin and Shannon feels they have insufficient knowledge and lack confidence at this stage in their course, which leaves them feeling insecure and ill prepared. Abby and Paige also identify the need for more preparatory information about the risk factors of cancer (Paige) and what to expect (Abby). The students have a range of issues that they feel unprepared for covering biomedical, physical, social and emotional issues.

\section{Cancer and end-of-Life}

Students linked their experiences of caring for cancer patients with care at the end of life. Lily describes how she is surprised by her positive experiences after she visits the Hospice:

Lily: "When you hear Hospice, what comes to my brain is... it's a place where people are dying or palliative. It was not like that.....they laugh, joke, dance, eat food, normal day. It was a good experience for me"

Lily expresses her preconceived thoughts of the hospice, as "people who are dying or 
palliative". Her visit to the hospice allows her to interact with cancer patients, and get a feel of what happens there. She describes cancer patients: "they can laugh, joke, dance, eat food", in other words they are normal people having a normal day. Cancer patients have been stigmatized for many years, as "dead, dying, in excruciating pain" (Sontag 1979). Now that Lily has had an experience at the hospice, her views of "dying with cancer" have changed. Lily is also happy to be herself in this environment as she is comfortable joking with cancer patients at the hospice. Francesca, like Lily, shares similar thoughts of hospice placements. She does not associate cancer patients as "walking around" and is surprised at her enjoyment of the experience in the hospice.

\section{Discussion}

Student nurses in this study report on their sensitivity to patients when providing emotional and supportive care in a range of different settings. Students like Marie and Ruby have previous experience as health care assistants and this enables them to feel confident in their care and ability to do emotional labour (EL). They can describe the skills involved in EL such as use of open-ended questions about feelings asking patients; 'how do you feel today?', making physical contact with patients through holding the patients' hand, the use of silence and they report their empathy and active listening skills; all aspects of patient-centered care and facilitative communication skills (Sparks \& Villagran 2010). Ruby and Marie seem to have a greater insight into their care giving skills and confidence in their skills than the other students. They understand the components of compassionate care and this enables them to feel competent and resourceful in their care; they can verbalize how they give personalized nursing care unlike the other students who feel fearful, lost and abandoned in relation to these aspects of care with people with cancer.

Student nurses in the present study hold views that equate cancer with a non-curable illness that results in death, views similar to those held by the general public in the UK (Sanford et al. 2011). This is despite the survivorship agenda in cancer care with cancer identified as a chronic rather than a terminal illness (DH 2012). The issue of the stigmatization of cancer due to cancer being seen as a death sentence didn't seem to differ between $2^{\text {nd }}$ and 3rd year groups, expressed as: "I don't mention the word cancer", by a third year student nurse and "those people" and "it" by a second year student nurse. 
Both groups of student nurses acknowledged feeling unprepared to deal with the strong emotions displayed by cancer patients, such as crying and anger. Students reported how they felt fearful, overwhelmed and worried about saying the wrong thing to patients with cancer.

The student nurses describe using blocking strategies and distancing techniques, such as avoiding cancer patients who were upset or crying or displays of anger as described by Summer, "I will cry, so I avoid them", and Beth as "the patients' journey...not mine", as a means of protecting themselves from stressful interactions with patients, which was also found in other studies (Gill \& Duffy 2010; Kruijver et al. 2000), in which student nurses tried to avoid dealing with emotional cancer patients for fear of getting "too involved" or "too attached". These findings emphasize the need to embed aspects of EL in pre-registration programmes (Smith 1992) to help students cope positively with emotional distress, through an exploration of the event or encounter and an evaluation of their attitudes and behaviours through reflection, action learning sets and other support mechanisms (Forneris \& Peden-McAlpine 2006).

Student nurses did report positive experiences when exposed to patients with cancer especially if they had a hospice placement where they found patients being "up and walking around" as a "good" experience, in comparison with other students who talked about the "crying" or "angry" cancer patient which they found as a "difficult" experience. Similar findings of this nature have been reported in Sanford et al's. (2011) study in which student nurses described their experiences as a "positive" one when cancer patients did not appear ill, for example in the outpatient clinic (Sanford et al. 2011), and a "bad" experience when the cancer patient was dying, for example in the intensive care unit. Student nurses who had a hospice placement felt much more positive and confident about caring for people with cancer and felt able to be themselves in this environment. Therefore hospice placements are one way to enable a more positive experience when caring at the end of life for those with cancer and other serious illnesses (Arber 2001).

Knowledge deficiencies related to the disease process of cancer and treatment modalities were evident and may have contributed to feelings of fear and the stigma of cancer. Whilst studies have shown that student nurses identify that health professionals place more emphasis on the physiological aspects of cancer (Sanford et al. 2011); 
psychosocial issues experienced by patients and observed by student nurses are sometimes taken for granted and remain hidden due to the pressures of time and staffing in the acute hospital setting (Bone 2002; Wilkinson 1991). There is evidence that students do not feel prepared regarding the psychosocial aspects of cancer care apart from the two students who had previous experience as health care assistants. Patients with cancer have expressed feeling unsupported during their illness trajectory despite receiving information concerning their diagnosis and treatment, describing their experience as "soul destroying" when nurses fail to get psychosocial care right (Thorne et al. 2008).

Educating student nurses about all aspects of patient-centered care involves helping them to do $E L$ and developing their social identity as a nurse. Education in $E L$ is essential as nurses personal identity is shaped during social interaction with patients (Smith 1992; Theodosius 2008). Nurses may use what is called surface or deep acting when interacting with patients and families (Hoschild 1983). Surface acting is about the nurse's professional persona where the nurse hides his/her real emotions where $\mathrm{s} / \mathrm{he}$ defends the sense of self and this results in a nurse who is pleasant, polite and nice but goes no further than that ( $\mathrm{Li}$ 2004). Deep acting is where the nurse commits herself to the needs of the patient as s/he gets to know and understand the patients' need, described as 'background knowledge' by Marie. Deep acting is expressive of personal identity and enables the nurse to empathize with the patient and to imagine the families' pain in an authentic manner avoiding stereotyped and distancing behaviour (Jourard 1971; Wilkinson 1991). However to develop student nurses skills in EL during preregistration education strategies need to be in place so that students can reflect on their experience of doing $E L$ and can be mentored in relation to developing EL skills as well as key communication skills that the students describe particularly coping with anger and strong emotions as well as breaking bad news. A more structured approach to the preparation of nurses for caring for those with cancer including the biomedical aspects of cancer will help to demystify cancer and shape the students perceptions of cancer as a curable as well as a chronic illness similar to other illnesses and not necessarily a terminal condition.

A major limitation of this study is that it was conducted in one school of nursing only. Additional data from other schools of nursing would extend the transferability of the 
findings and the rigour of the study. One of the focus groups had only 4 participants and it is preferable for a focus group study to ideally have 6-8 participants in each group. In the future it is possible to extend the study to other schools of nursing and to conduct studies of innovative approaches to cancer care using action learning methodology and a before and after design (Cooper 2012).

\section{Conclusion}

Student nurses' experiences of caring for cancer patients have highlighted areas for development in the pre-registration curricula. The findings from this study show that a graduated and continual experiential training programme regarding care of the patient with cancer is needed. This development should be graduated across the three years of the course and reflect attitudes to cancer, an enhanced knowledge base of the biology of cancer, risk factors, treatment modalities, psychosocial care and specific skills in communication and reflective practice such as breaking bad news, handling strong emotions and providing supportive care. EL and how it is experienced in practice needs to be discussed and reflected upon and this will support all levels of professional preparation in relation to patients with cancer. Additionally, support and clinical supervision through mentoring in the clinical area will increase student's confidence and psychosocial wellbeing and will help with the self-development and insight needed for EL and caring skills for those with cancer.

\section{Conflict of interest statement}

None declared 


\section{References}

Arber A. (2001) Student nurses' knowledge of palliative care: Evaluating an education module. International Journal of Palliative Nursing 7, 597-603.

Barbour R.S. \& Kitzinger J. (1990) Developing focus group research: politics, theory and practice. Sage Publications, London UK.

Bone D. (2002) Dilemmas of emotion work in nursing under market-driven health care. International. Journal of Public Sector Management 15, 140-150.

Bradbury-Jones C, Sambrook S \& Irvine F (2009) The phenomenological focus group: an oxymoron? Journal of Advanced Nursing 65, 663-71.

Colaizzi P. (1978) Psychological research as the phenomenologist views it. In Valle R, King, M., (Eds) Existential phenomenological alternatives for psychology. Oxford University Press, Oxford, UK 48-71.

Corner J. (1993) The impact of nurses' encounters with cancer on their attitudes towards the disease. Journal of Clinical Nursing 2, 363-372.

Cooper L.R. (2012) Teaching nursing students about palliative care. Unpublished MSc dissertation, Western Governors University, Washington DC, USA.

Co^te'-Arsenault D. \& Morrison-Beedy D. (2001) Women's voices reflecting changed expectations for pregnancy after perinatal loss. Journal of Nursing Scholarship 33, 239244.

Cunningham S.M., Copp G., Collins B. \& Bater, M. (2006) Pre-registration nursing students' experience of caring for cancer patients. European Journal of Oncology Nursing 10, 59-67.

Denzin N.K. (1989) The Research Act. 3rd ed. Prentice Hall, Englewood Cliffs, New Jersey, US.

DH. (2012) Quality of life of cancer survivors in England. Department of Health, London, UK

Fabricius J. (1991) Learning to work with feelings - psychodynamic understanding and small group work with student nurses. Nurse Education Today 11, 134-142.

Forneris S. \& Peden-McAlpine C. (2006) Contextual Learning: A Reflective Learning Intervention for Nursing Education. International Journal of Nursing Education Scholarship, 3, 1-20 http://faculty.ksu.edu.sa/hisham/Documents/Medical\%20Education/English/Nursing\%20Educatio n/55.pdf [Accessed 11th October 2013]

Gill F. Duffy A. (2010) Caring for cancer patients on non-specialist wards. British Journal of Nursing 19, 761-767. 
Halling S. \& Leifer M. (1991) The theory and practice of dialogal research. Journal of Phenomenological Psychology 22, 1-15.

Halling S., Kunz G. \& Rowe J.O. (1994) The contributions of dialogal psychology to phenomenological research. Journal of Humanistic Psychology 34, 109-131.

Hjörleifsdóttir E. \& Carter D.E. (2000) Communicating with terminally ill cancer patients and their families. Nurse Education Today 20, 646-653.

Hoschild A. (1983) The Managed Heart. University of California Press, Berkeley, US.

Hughes P., Hancock C. \& Cooper K . (2012) Non-communicable diseases: calling healthcare educators to action. Nurse Education Today 32 757-759.

Husserl, E. (2001) The Shorter Logical Investigations, Translated by J.N. Findlay, London, Routledge.

Hyland J.R. \& Hawkins M.C. (2009) High-fidelity human simulation in nursing education: a review of literature and guide for implementation. Teaching and Learning in Nursing 4, 14-21.

Iranmanesh S., Axelsson K., Savenstedt S. \& Haggstrom T. (2009) A caring relationship with people who have cancer. Journal of Advanced Nursing 65 1300-1308.

Jarrett N. \& Payne S. (2000) Creating and maintaining 'optimism' in cancer care communication. International Journal of Nursing Studies 37, 81-90.

James N. (1989) Emotional labour: skill and work in the social regulation of feelings. Sociological Review 37, 15-42.

Jourard S.M. (1971) The Transparent Self. Litton Educational Publishing Inc. London,UK

Kav S., Citak E.A., Akman A. \& Erdemir, F. (2012) Nursing students' perceptions towards cancer and caring for cancer patients in Turkey. Nurse Education in Practice 13, 4-10. http://download.journals.elsevierhealth.com/pdfs/journals/14715953/PIIS1471595312001059.pdf [Accessed 11th October 2013]

Kearney N., Miller M., Paul J., Smith K. \& Rice, A.M. (2003) Oncology Health Care professionals' attitudes to cancer: a professional concern. Annals of Oncology 14, 5761.

Knight M. \& Field D. (1981) A silent conspiracy: coping with dying cancer patients on an acute surgical ward. Journal of Advanced Nursing 6, 221-229.

Krueger R.A. (1988) Focus Groups: A Practical Guide for Applied Research. Sage Publications, Thousand Oaks, CA, USA.

Krueger R.A. \& Casey M.A. (2000) Focus Groups: A Practical Guide for Applied Research, 3rd ed. Sage, Thousand Oaks, CA USA 
Kruijver I.P., Kerkstra A., Bensing J.M. \& van de Wiel H.B. (2000) Nurse-patient communication in cancer care, a review of the literature. Cancer Nursing 23, 20-31.

Lacey A. (2006) The Research Process. In: Gerrish, K., Lacey, A. (Eds) The Research Process in Nursing, 5th ed. Oxford, Blackwell Publishing, UK 16-30.

Langridge D. (2007) Phenomenological Psychology. Theory, Research and Method. Pearson Education Limited, Essex:, UK

Li S. (2004) Symbiotic niceness': constructing a therapeutic relationship in psychosocial palliative care. Social Science and Medicine 58, 2571-2583.

Meleis A. I. (1996) Culturally competent scholarship: Substance and rigor. Advances in Nursing Science 19, 1-16.

Mohan S., Wilkes, L.M., Ogunsiji O. \& Walker A. (2005) Caring for patients with cancer in non-specialist wards: the nurse experience. European Journal of Cancer Care 14, 256-263.

Morse J.M. \& Field P.A. (1995) Qualitative Research Methods for Health Professionals. Sage, California, US.

Sadala M.L. \& da Silva F.M. (2009) Taking care of terminal patients: nursing students' perspective. Revista da Escola de Enfermagem da U S P 43, 287-294.

Sales A. (2010) Walking on Eggshells. A Caregiver's Guide to Practical, Real life Direction on What to Say and Do When a Loved one Has a Life Limiting IIIness. Author House, London, UK.

Sanford, J., Townsend-Rocchiccioli J., Quiett K. \& Trimm, D. (2011) “I See My Mother's Face". Student nurse experiences caring for cancer patients. European Journal of Oncology Nursing 15, 46-52.

Schrock M.M. \& Swanson E. A. (1981) The effect on nursing students of direct-care experience with death and dying. Nursing Forum 20, 213-219.

Silverman D. (2011) Interpreting Qualitative Data. 4th ed. Sage Publications, London,UK.

Smith P. \& Gray B. (2001) Reassessing the concept of emotional labour in student nurse education: role of link lecturers and mentors in a time of change. Nurse Education Today 21, 230-237.

Smith P. (1992) The emotional labour of nursing. Macmillan, London, UK.

Sontag S. (1979) IIIness as metaphor. Allen Lane, London, UK.

Sorrell J.M. \& Redmond G.M. (1995) Interviews in qualitative nursing research: differing approaches for ethnographic and phenomenological studies. Journal of Advanced Nursing 21, 1117-1122. 
Sparks L. \& Villagran M. (2010) Patient and provider interaction. Polity, Cambridge, UK. Theodosius C. (2008) Emotional labour in health care. Routledge, London, UK.

Thorne S.E., Hislop G., Armstrong E.A. \& Oglov V. (2008) Cancer care communication: The power to harm and the power to heal? Patient Education \& Counseling 71, 34-40.

Topping A. (2006) The Quantitative-Qualitative Continuum. In: Gerrish, K., Lacey, A., (Eds.), The Research Process in Nursing. 5th ed. Blackwell Publishing, Oxford, UK pp. 155- 172.

Webb C. (2003) Editor's note: introduction to guidelines on reporting qualitative research. Journal of Advanced Nursing 42, 544- 545.

Webb C. \& Kevern J. (2001) Focus groups as a research method: a critique of some aspects of their use in nursing research. Journal of Advanced Nursing 33, 798-805.

Wilkinson S. (1991) Factors which influence how nurses communicate with cancer patients. Journal of Advanced Nursing 16, 677-688.

Wilkinson S. (1998) Focus group methodology: a review. International Journal of Social Research Methodology 3, 181-203.

Wood C. \& Ward J. (2000) A general overview of the cancer education needs of non specialist staff. European Journal of Cancer 9, 191-196.

Wojnar D.M. \& Swanson K.M. (2007) Phenomenology: An exploration. Journal of Holistic Nursing 25, 172-180. 